\title{
Influencing factors of price fluctuation in China's carbon market
}

\author{
WeiQi $^{1}$, Bian Yuanyuan ${ }^{2}{ }^{2}$, Yang Xuejuan ${ }^{3}$ \\ ${ }^{1,3}$ Lanzhou University of Technology School of Economics and Management Lanzhou, Gansu, China \\ $2^{*}$ Lanzhou University of Technology School of Economics and Management Lanzhou, Gansu, China
}

\begin{abstract}
Carbon emission trading is an important countermeasure for countries around the world to cope with the challenge of climate change. Price signals in the carbon market play an important stabilizing role. Therefore, research on the factors affecting carbon price fluctuations is of great significance. Based on this, an empirical study on the fluctuation factors of carbon price in China's pilot carbon market showed that: gross industrial output, coal consumption and the number of extreme weather have a positive impact on carbon prices, while the technology innovation index has a negative impact on carbon prices. This article puts forward suggestions on the construction of the carbon market, stabilizes carbon prices, and promotes the development of China's carbon market.
\end{abstract}

\section{Introduction}

Faced with the various challenges brought about by global climate change, carbon emission reduction has become an important measure for all countries to deal with. China has also actively participated in it and launched its own emission reduction plan: strive to reach a peak in carbon dioxide emissions before 2030, and strive to achieve carbon neutrality by 2060. In 2019, China's carbon dioxide emissions per unit of GDP dropped by approximately $18.2 \%$ and $48.1 \%$ compared with 2015 and 2005 , respectively. At present, China has a total of 2,837 key emission units participating in the pilot carbon market. As of the end of August 2020, the cumulative transaction volume of the seven pilot carbon market allowances was 406 million tons, and the cumulative transaction volume was approximately 9.28 billion RMB. The key to combating climate change is to establish a carbon price signal and a carbon market. A scientific and reasonable carbon price signal is the primary prerequisite for achieving an effective unity of the environment and economy. At the same time, it guides and promotes enterprises to achieve carbon emission reduction targets and increase the reality of low-emissions enterprises. Earnings to further stabilize the carbon trading market. Foreign scholars have done many researches on the formation mechanism of carbon price, but most of them are based on the influence factors of EU on carbon price. It mainly focuses on the close relationship between carbon price and energy price (crude oil, natural gas, coal), weather conditions, electricity price and macro economy [1-3]. With the continuous development of China's carbon trading market, there are more and more researches on the influencing factors of carbon price in China. Du Ziping ${ }^{[4]}$ and Wang Danzhou ${ }^{[5]}$, found that China's carbon market price is related to energy structure, weather and macro economy. In addition to the above-mentioned influencing factors, some scholars have studied the influence of quota amount, enterprise emission reduction cost, imbalance between supply and demand in carbon market, major events, international market demand and exchange rate on carbon price. Looking at the existing literature, scholars at home and abroad have focused on analysing the relationship between energy price, macroeconomic activities, weather and other factors and carbon market, while there are few literatures that bring market supply, market demand, government price limit and international market into the influencing factors of carbon price. Therefore, this paper will expand the existing literature, study the relationship between market supply and demand, government price limit, international market and carbon market, and give reasonable policy suggestions through quantitative analysis, combined with China's carbon trading characteristics and trading system. Based on the current domestic research and analysis of carbon price in China, this paper will further study the influencing factors of China's carbon market price, control risks, avoid market instability caused by excessive fluctuations in carbon price, guide social subjects to turn to low-carbon production and lifestyle, ensure the competitiveness of each subject participating in carbon trading, and provide feasible solutions for the comprehensive development of the national carbon market.

\section{China's carbon market price formation mechanism}

\subsection{Trend of carbon price in China's carbon market}

From the transaction price chart 1 , the transaction prices of the seven carbon trading pilot markets are quite 
different. Among them, although the carbon prices in Guangdong, Hubei and Tianjin pilot markets fluctuated, they were generally stable. The carbon transaction price in Beijing and Shanghai carbon pilot markets showed a trend of first decreasing and then increasing, and the carbon market lacked stability as a whole. The trading price of carbon emission rights in Shenzhen carbon market shows an overall downward trend. The carbon price in Chongqing's carbon market also showed an overall downward trend, with great volatility, and the carbon price remained low and the market stability declined. The data comes from the carbon $\mathrm{K}$ line of China's carbon emission trading network.

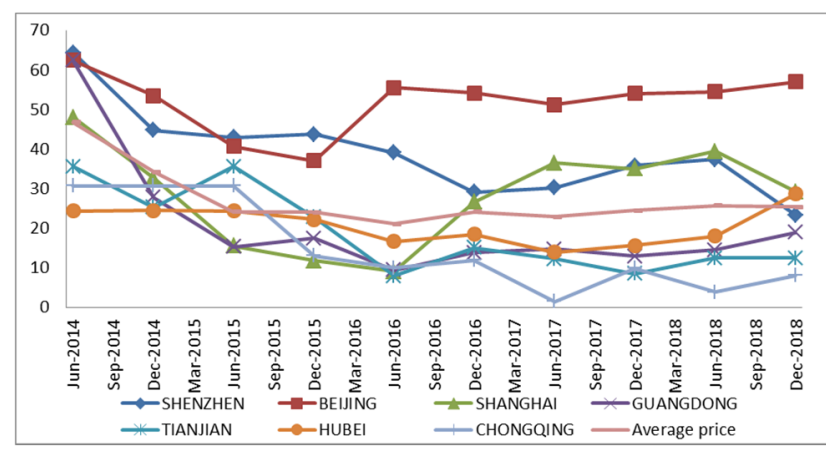

Fig1. Transaction price chart of China's pilot carbon market (Unit: $\mathrm{RMB} / \mathrm{tCO} 2$ )

\subsection{Factors affecting the change of carbon price}

\subsubsection{Supply factors affecting the change of carbon trading price}

The supply in China's carbon trading market mainly refers to the total amount of carbon quota, which is mainly distributed by the government to each carbon trading pilot according to the macro carbon emission reduction target, and each carbon trading pilot is distributed according to the actual emission reduction situation reported by enterprises and relevant systems. However, the carbon offset ratio allowed by each carbon trading market increases the total carbon quota in China to a certain extent, that is, the total supply increases accordingly. With the transformation of China's industrial structure, under the general trend of global energy conservation and emission reduction, the total supply of carbon quota will decrease, and the price of carbon emission right in China's carbon market will rise while the demand remains unchanged.

\subsubsection{Demand factors affecting the change of carbon trading price}

In China's carbon trading market, the main factors that cause changes in the total demand of carbon quotas are: energy output factors, macroeconomic level factors, climate and environmental changes, and production technology level factors of enterprises. The change of energy consumption will affect the fluctuation of carbon price, and the change of macro-economic level will have a direct impact on the production of enterprises, while the changes of climate and environment factors and production technology level of enterprises will have a direct impact on the marginal income and development strategy of enterprises, which will lead to the shift of carbon quota demand curve, and the change of carbon price when supply factors are not considered.

1. The macroeconomic situation. A better macroeconomic situation can drive the production of enterprises, increase the demand for resources, and thus increase the emission of greenhouse gases.

2. Energy output. According to China's existing energy consumption structure, coal consumption accounts for $20 \%$ of the total, and coal consumption will produce a large amount of greenhouse gases. It can be seen that if coal consumption can be controlled, on the one hand, the emission of greenhouse gases will be reduced, on the other hand, the stability of carbon prices will be maintained.

3. Production technology of enterprises. The actual carbon emission of the emission subject depends not only on the production level of the emission subject, but also on its emission reduction ability, and the emission reduction technology determines the emission reduction ability. This paper selects the science and technology innovation indexes of seven provinces and cities as explanatory variables.

4. Weather conditions. Extreme weather conditions will directly affect the use of carbon energy, increase the demand for carbon energy, and then affect the fluctuation of carbon price.

\subsubsection{Government price limit factors affecting the change of carbon trading price}

In China's carbon emissions trading market, in addition to supply and demand factors, the government's price limit on the carbon market will also have a certain impact on carbon prices. Since the development of China's carbon trading market is not mature enough, the implementation of the price limit system by the government can not only ensure the healthy and stable development of the carbon market itself, but also protect the interests of carbon emission enterprises. However, the government's price limit policy can't reflect the actual changes of supply and demand, and it can't be in line with the international carbon market price.

\section{Empirical analysis}

\subsection{Data source}

Since the price of carbon emission right is the indicator reflecting the stability of China's carbon market, the interpreted variable selected in this paper is the price of carbon quota, with the unit of RMB/ton. Gross industrial output value, coal consumption, science and technology innovation index and extreme weather in various provinces and cities are selected as explanatory variables. Considering the lag of macroeconomic data, the numerical value with one period lag is used as the explanatory variable. For the data of extreme weather times, this paper selects the daily observed minimum temperature value of the effective dates from 2013 to 2018 in seven carbon pilot 
areas to subtract the national average minimum temperature. If the difference between the obtained minimum temperatures is less than 0 , it is regarded as extreme temperature, otherwise it is not extreme temperature. The data comes from wind database, and the following is the statistical table of the mean value of each variable.

Table1. Average value of each variable data

\begin{tabular}{cccccc}
\hline Pilot area & $\begin{array}{c}\text { carbon } \\
\text { price }\end{array}$ & $\begin{array}{c}\text { Gross industrial } \\
\text { output value (100 } \\
\text { million RMB) }\end{array}$ & $\begin{array}{c}\text { Coal } \\
\text { consumption }\end{array}$ & $\begin{array}{c}\text { Science and } \\
\text { technology } \\
\text { innovation index }\end{array}$ & $\begin{array}{c}\text { Frequency of } \\
\text { extreme } \\
\text { temperature }\end{array}$ \\
\hline BJ & 46.31 & 18227.22 & 1186.10 & 87.82 & 147.67 \\
SH & 24.80 & 31364.41 & 4775.68 & 66.98 & 150.33 \\
GD & 28.76 & 19179.46 & 16114.82 & 47.94 & 126.67 \\
SZ & 41.72 & 26586.55 & 12008.64 & 10.04 & 127.00 \\
TJ & 16.33 & 27882.78 & 4490.22 & 54.06 & 146.50 \\
HB & 20.02 & 13005.92 & 11732.62 & 25.39 & 153.50 \\
CQ & 12.98 & 20860.16 & 5746.08 & 27.89 & 147.83 \\
\hline
\end{tabular}

\subsection{Empirical results}

According to the above analysis of various factors affecting the price of carbon emission rights, this paper establishes a multiple regression model as follows:

$$
\mathrm{Y}=B_{0}+B_{1} X_{1}+B_{2} X_{2}+B_{3} X_{3}+B_{4} X_{4}+U
$$

Table2. Statistical results

\begin{tabular}{lrlll}
\hline \hline \multicolumn{1}{c}{ Variable } & Coefficient & Std. Error & t-Statistic & Prob. \\
\hline \hline X1 & 0.118719 & 0.014440 & 8.221828 & 0.0074 \\
X2 & 0.210363 & 0.034414 & 6.112780 & 0.0095 \\
X3 & -0.136179 & 0.022329 & 6.098678 & 0.0095 \\
X4 & 0.245009 & 0.031715 & 3.725316 & 0.0082 \\
C & -6818.296 & 98.10340 & -69.50112 & 0.0092 \\
\hline \hline R-squared & 0.992222 & Mean dependent var & 24.75500 \\
Adjusted R-squared & 0.961112 & S.D. dependent var & 11.61139 \\
S.E. of regression & 2.289771 & Akaike info criterion & 4.369688 \\
Sum squared resid & 5.243050 & Schwarz criterion & 4.196154 \\
Log likelihood & -8.109063 & Hannan-Quinn criter. & 3.675018 \\
F-statistic & 31.89357 & Durbin-Watson stat & 3.453371 \\
Prob(F-statistic) & 0.012103 & & \\
\hline \hline
\end{tabular}

According to the data in Table 2, the model estimation results are as follows:

$$
\mathrm{Y}=-6818.296+0.118719 \mathrm{X}_{1}+0.210363 \mathrm{X}_{2}-
$$$$
0.136179 \mathrm{X}_{3}+0.245009 \mathrm{X}_{4}
$$

$$
(0.014440)(0.034414)(0.0022329)(0.031715)(98.10340)
$$

\subsection{Test of model statistics}

1. Economic significance test: The model estimation results show that the carbon price increases by $11.87 \%$ for every 100 million RMB increase in gross industrial output value under the assumption that other variables remain unchanged; assuming that other variables remain unchanged, when coal consumption increases by 10,000 tons, carbon price increases by $21 \%$; under the assumption that other variables are unchanged, the carbon price decreases by $13.62 \%$ for every $1 \%$ increase in the science and technology innovation index; assuming that other variables remain unchanged, the carbon price increases by $24.5 \%$ for every day when the frequency of extreme temperature increases.

2. Goodness-of-fit test: $R^{2}$ is used to measure the degree of fit. In this paper, $\mathrm{R}^{2}=0.992222$, indicating that the explanatory power of the sample regression line is $99 \%$, that is, $99 \%$ of the carbon price in my country's seven carbon pilot regions from 2013 to 2018 can be explained by changes in other variables. The fit of the model is relatively high.

3. T-test: At the significance level of $5 \%$, the value of parameter T-test is greater than T-statistic, which indicates that each parameter is significantly non-zero, and the variables of total industrial output value, scientific and technological innovation index of coal consumption and frequency of extreme weather have significant influence on the model.

4. F-test: In the empirical test, the probability value of $\mathrm{F}$ is 0.000 , which passes the test, that is to say, the linear relationship of the model is established at $95 \%$ confidence level.

5. Stability test: From the regression results, it is found that the coefficients and significance of each variable in the model have no significant changes, so the model is stable.

\subsection{Eliminate multicollinearity}

In order to eliminate multicollinearity, this paper will make a univariate regression of $Y$ to $X_{1}, X_{2}, X_{3}$ and $X_{4}$, and the results are shown in Table 3:

Table3. Univariate regression results

\begin{tabular}{ccccc}
\hline Variable & $\mathrm{X}_{1}$ & $\mathrm{X}_{2}$ & $\mathrm{X}_{3}$ & $\mathrm{X}_{4}$ \\
\hline Parameter estimator & 0.054967 & 0.002082 & --0.002413 & 0.090395 \\
$\mathrm{~T}$ & 1.559009 & 0.180334 & -0.349390 & 1.605306 \\
$\mathrm{R}^{2}$ & 0.377965 & 0.338064 & 0.329615 & 0.391821 \\
\hline
\end{tabular}


According to the above statistics, the size of $\mathrm{R}^{2}$ is sorted as follows: $\mathrm{X}_{4}, \mathrm{X}_{1}, \mathrm{X}_{2}$, and $\mathrm{X}_{3}$. Based on $\mathrm{X}_{2}$, the other three explanatory variables are sequentially added to perform stepwise regression.

First, $\mathrm{X}_{1}$ is added to obtain the result:

$$
\begin{gathered}
Y=-243.684+0.009759 X_{2}+0.070720 X_{1} \\
T=(4.959741)(5.863561), R^{2}=0.524087
\end{gathered}
$$

Taking $\quad \alpha$ as $5 \%, \mathrm{t}_{0.025}(2)=4.3027$, then the t-test of the $\mathrm{X}_{1}$ parameter is significant.

Add $\mathrm{X}_{3}$ to get the result:

$\mathrm{Y}=576.7686+0.074170 \mathrm{X}_{2}+0.04202 \mathrm{X}_{1}-0.049236 \mathrm{X}_{3}$
$\mathrm{~T}=(4.58185)(6.691865)(-5.656811), \mathrm{R}^{2}=0.608527$

Taking $\alpha$ as $5 \%, \mathrm{t}_{0.025}(2)=4.3027$, then the $\mathrm{t}$-test of the $\mathrm{X}_{3}$ parameter is significant.

Add $\mathrm{X}_{4}$ to get the result:

$$
\begin{array}{r}
\mathrm{Y}=-6818.296+0.118719 \mathrm{X}_{1}+0.210363 \mathrm{X}_{2-} \\
0.136179 \mathrm{X}_{3}+0.245009 \mathrm{X}_{4} \quad(5) \\
\mathrm{T}=(8.221828)(6.27180)(6.098678)(3.725316), \mathrm{R}^{2}=0.99222
\end{array}
$$

Taking $\alpha$ as $5 \%, \mathrm{t}_{0.025}(2)=4.3027$, then the t-test of the $\mathrm{X}_{4}$ parameter is not significant, so it is eliminated.

So the equation (6) is the result of eliminating multicollinearity:

$$
Y=-6818.296+0.118719 X_{1}+0.210363 X_{2}-0.136179 X_{3}(6)
$$

Under the assumption that other variables remain unchanged, for every 100 million RMB increase in industrial production value, the carbon price increases by $11.87 \%$; under the assumption that other variables remain unchanged, when coal consumption increases by 10,000 tons, the carbon price increases by $21 \%$; under the assumption that other variables remain unchanged, for every $1 \%$ increase in the science and technology innovation index, the carbon price drops by $13.62 \%$.

From the equation obtained by regression, the overall significance of the model is good, indicating that the overall fitting degree of the four explanatory variables, i.e. the total industrial output value, coal consumption, scientific and technological innovation index and the frequency of extreme weather, is good, and the coefficient symbols of each explanatory variable are consistent with expectations.

\section{Conclusions and suggestions}

At present, China's carbon trading market has entered a stage of rapid development, but compared with the mature carbon emission trading markets in western countries, China's carbon market is still facing many challenges such as obvious fluctuations in carbon prices and negative market sentiment. Therefore, this paper makes an empirical analysis of the influencing factors of carbon price in seven pilot carbon markets in China, and draws two conclusions: (1) The total industrial output value, coal consumption and the frequency of extreme weather have a positive impact on carbon price; (2) Science and technology innovation index has a negative impact on carbon price. Based on this, the following suggestions are put forward for the development of China's carbon market:

1. Encourage technological innovation of enterprises

By establishing incentive mechanism, the government can reward enterprises that have made outstanding contributions to emission reduction, and strengthen publicity in society, so that enterprises have more motivation to innovate in technology and choose clean energy.

2. Pay attention to the energy market price

Due to economic development, the relationship between the energy market and the carbon market has become closer. Therefore, in order to maintain the stability of future carbon trading market prices, market regulators must pay close attention to changes in energy market prices. At the same time, the energy reserve system should be improved to stabilize energy prices by releasing energy reserves when energy prices rise sharply, and increasing reserves when energy prices fall to increase energy prices, thereby stabilizing carbon prices.

3. Encourage innovative carbon financial products

From the empirical results of this paper, the change of total industrial output value will have an impact on carbon price, and the explanatory power is about $11 \%$, which shows that the long-term linkage between carbon trading market and macroeconomic indicators is not strong. Therefore, China should accelerate the innovation of carbon financial products and rationally use policy tools to promote the effective operation of carbon trading market.

4. Strengthen the monitoring of extreme weather conditions indicators

China's carbon trading authorities should strengthen the monitoring of weather conditions such as rainfall, timely and accurately predict carbon price fluctuations that may be caused by changes in weather conditions, and formulate reasonable countermeasures to ensure the stable development of the carbon trading market.

\section{Acknowledgments}

This article is one of the phased achievements of the National Natural Science Foundation of China project $<$ Experimental Research on the Efficiency of Carbon Emissions Trading and the Construction of Regulation Mechanism under the Impact of Uncertainty>(71963024).

\section{References}

1. Creti A, Jouvet P A, Mignon V.(2012) Carbon price drivers: Phase I versus Phase II equilibrium[J]Energy Economics ,34: 327-334

2. MANSANET-BATALLER M,PARDO A,VALOR E.(2007)CO2prices,energy and weather[J].The Energy Journal, 28(3):73-92.

3. ALBEROLA E,CHEVALLIVER J,CHEZE B. (2008)Price drivers and structural breaks in european carbon prices 2005-2007[J].Energy Policy, 
36(2):787-797.

4. Du Ziping, Liu Fucun.(2018)Research on my country's Regional Carbon Emission Rights Price and Its Influencing Factors-An Empirical Analysis Based on GA-BP-MIV Model[J]. Price Theory and Practice, 6: 42-45.

5. Wang Danzhou, Yang Detian.(2018)Drivers of China's carbon emissions trading price[J]. Journal of Capital University of Economics and Business, 20(05):87-95. 